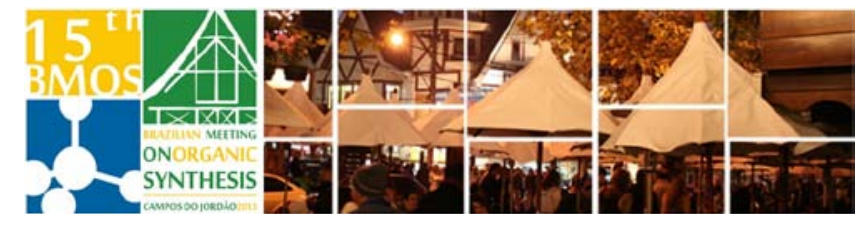

\title{
Reactions of bis-propargyl cycloalkanones with gold and silver catalysts
}

\author{
André L. Desiderá, Leandro de C. Alves, Amanda M. Claro, Abner A. Domingos, \\ Marco A. B. Ferreira, Kleber T. de Oliveira and Timothy J. Brocksom*
}

Departamento de Química, Universidade Federal de São Carlos, São Carlos-SP, 13565-905, Brazil

*Corresponding author: e-mail:brocksom@terra.com.br. www.lqbo.ufscar.br.

Keywords: bis-propargyl cycloalkanones, gold/silver catalysis, internal tris-ketal

\section{INTRODUCTION}

We have already demonstrated that the reactions of 2,2bis-allyl cycloheptenones with $\mathrm{Pd}$ and Ru catalysts lead to intriguing internal tris-ketal molecules such as $4 .{ }^{1}$ We have now extended our studies to include the related bispropargyl derivatives (1-3), with the use of gold catalysts, with and without silver compounds as co-catalysts.

\section{RESULTS AND DISCUSSION}

The bis-propargyl compounds (1-3) were prepared from the corresponding cycloalkanones, by reaction with propargyl bromide and base. (1-3) were then subjected to reactions catalyzed by gold (5 mol\%) and silver (10 mol\%) compounds in dichloromethane, with the addition of 6 equivalents of water. The products (4-6) were obtained as described in Table 1 (see Scheme 1).

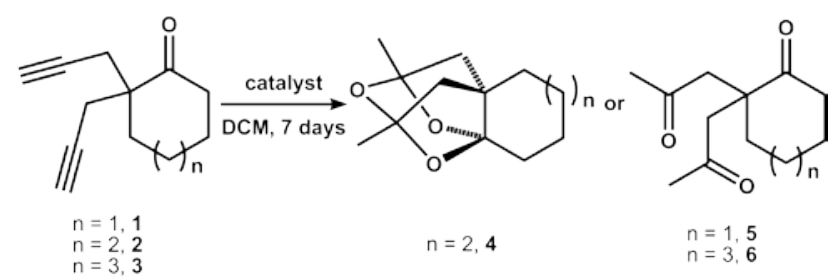

Scheme 1.

Table 1. Reactions of $\mathbf{1}$ leading to $\mathbf{4 , 2}$ to $\mathbf{5}$ and $\mathbf{3}$ to 6.

\begin{tabular}{|c|c|c|c|c|}
\hline Entry & Catalyst & $1 \rightarrow 4$ & $2 \rightarrow 5$ & $3 \rightarrow 6$ \\
\hline 1 & $\mathrm{HAuCl}_{4} \cdot 3 \mathrm{H}_{2} \mathrm{O}$ & $83 \%$ & $92 \%$ & $21 \%$ \\
\hline 2 & $\mathrm{AuCl}$ & $18 \%$ & $44 \%$ & $4 \%$ \\
\hline 3 & $\mathrm{Au}\left(\mathrm{PPh}_{3}\right) \mathrm{Cl}$ & $0 \%$ & $0 \%$ & $0 \%$ \\
\hline 4 & $\mathrm{AuCl} / \mathrm{AgBF}_{4}$ & $8 \%$ & $40 \%$ & $2 \%$ \\
\hline 5 & $\mathrm{Au}\left(\mathrm{PPh}_{3}\right) \mathrm{Cl} / \mathrm{AgBF}_{4}$ & $100 \%$ & $99 \%$ & $3 \%$ \\
\hline 6 & $\mathrm{AuCl} / \mathrm{AgSbF} \mathrm{F}_{6}$ & $7 \%$ & $57 \%$ & $2 \%$ \\
\hline 7 & $\mathrm{Au}\left(\mathrm{PPh}_{3}\right) \mathrm{Cl} / \mathrm{AgSbF} \mathrm{F}_{6}$ & $66 \%$ & $99 \%$ & $4 \%$ \\
\hline 8 & $\mathrm{AgBF}_{4}$ & $7 \%$ & $4 \%$ & $1 \%$ \\
\hline 9 & $\mathrm{AgSbF}_{6}$ & $7 \%$ & $8 \%$ & $1 \%$ \\
\hline
\end{tabular}

The ring size is obviously conclusive in directing the reaction towards the internal tris-ketal4 (7-member), or the bis-acetonyl derivatives 5 and $\mathbf{6}$.

In order to rationalize the influence of the size of the fused ring on quite distinct reaction pathways (Scheme 1), we proposed a theoretical study of the products' Gibbs free energies. After a search for the lowest energy conformations of each of the possible products (Figure 1), the Free energies of each compound were calculated, and grouped in pairs of the same ring size. The results are presented in Table 2, using the B3LYP/6-31+G(d,p) level of theory.
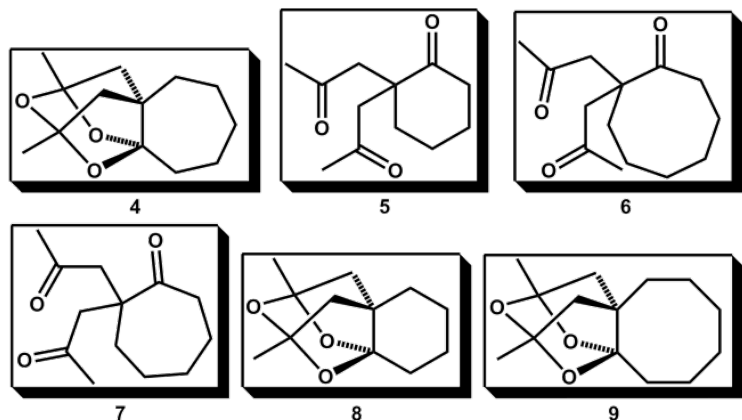

Figure 1.

Table 2. Free energies of compounds 4 to $\mathbf{9}$.

\begin{tabular}{|c|c|c|}
\hline Compound & Energy & $\Delta \mathrm{E}$ (ketal-keto) \\
\hline 4 & -732.847444 & \multirow{2}{*}{-0.198290} \\
\hline 7 & -732.847128 & \\
\hline 8 & -693.55814 & \multirow{2}{*}{3.702877} \\
\hline 5 & -693.564041 & \\
\hline 9 & -772.125118 & \multirow{2}{*}{3.437445} \\
\hline 6 & -772.130596 & \\
\hline
\end{tabular}

\section{CONCLUSION}

We have found that the 7-member substrate 2 leads to the intriguing internal tris-ketal 4, whereas the 6- and 8member analogues $\mathbf{1}$ and $\mathbf{3}$ give the expected hydration products $\mathbf{5}$ and $\mathbf{6}$. The presence of silver co-catalysts and additional water has a substantial effect on the yields.

The experimental results have found agreement with the calculations shown in Table 2, which express a very unusual thermodynamic stability for the seven-membered fused system 4, when compared to the 6- and 8membered analogues 8 and $\mathbf{9}$.

\section{ACKNOWLEDGEMENTS}

Thanks are due to the São Paulo Research Foundation (FAPESP, grants 2011/13993-2, 2013/02311-3 and 2013/06532-4), CNPq, and CAPES: and Firmenich for the donation of $(R)-(-)$-carvone.

\section{REFERENCES}

1 Frederico, D.; Brocksom, T. J.; Brocksom, U. "A novel ring closing metathesis reaction product: internal tris-ketal formation from a 2,2-bispropargyl cycloheptenone" In: XI BMOS, 2005, Canela, RS. 